\title{
Farmer Bargaining Power and Market Information Services
}

\author{
Pierre Courtois* Julie Subervie ${ }^{\dagger}$
}

This draft: January 8, 2013

\begin{abstract}
In many Sub-Saharan African countries, farmers typically have a choice between selling their products to traders who travel between villages and markets and transporting their products to the nearest market themselves. Because of communities' remoteness and poor communications with marketplaces, farmers' uncertainty about market prices is usually high. Traders may take advantage of farmers' ignorance of the market price and extract a rent from them by offering very low prices for their products. In this article, we model bargaining interactions between a farmer and a trader who incur different transportation costs, and we study how price information affects the bargain and the balance of power. We then estimate the causal effect of a Market Information System (MIS) working through mobile phone networks on Ghanaian farmers' marketing performances. We find that farmers who have benefited from the MIS program received significantly higher prices for maize and groundnuts: about $12.7 \%$ more for maize and $9.7 \%$ more for groundnuts than what they would have received had they not participated in the MIS program. These results suggest that the theoretical conditions for successful farmer use of MIS may be met in field.
\end{abstract}

Key words: market information system, developing countries, market power.

JEL: D81, D83, O12, O13, C78.

*INRA, UMR 1135 LAMETA, F-34000 Montpellier - France. Tel: +33 434435954. email: courtois@supagro.inra.fr

${ }^{\dagger}$ INRA, UMR 1110 MOISA, F-34000 Montpellier - France. Tel: +33 499613131. email: subervie@supagro.inra.fr This research would not have been possible without the full cooperation of Esoko-Ghana. We are particularly grateful to Sarah Bartlett and Isaac Boateng for their research assistantship in the field. Funding for this research was provided by AFD and CTA. 


\section{Introduction}

The price that smallholders receive for their agricultural products has great implications for poverty alleviation. Increased profitability for farmers may lead them to change their production, investment, and marketing decisions: they may farm land more intensively, sell in larger quantities, invest in productive assets, adopt new agricultural technologies, move land out of nonagricultural use, switch crops, or engage in spatial arbitrage (Jensen, 2010). In many Sub-Saharan African countries, farmers typically have a choice between selling their products to traders who travel back-and-forth between villages and markets or transporting their products themselves to the nearest market (Fafchamps and Hill, 2005). Many farmers opt for trader pick-up, despite the fact that traders may take advantage of a farmer's ignorance of the market price, seeking to extract a rent from them by offering very low prices for their products (Fafchamps and Hill, 2008; Mérel, Sexton, and Suzuki, 2009). Previous studies have examined how farmers decide whether or not to participate in the market (Goetz, 1992; Key, Sadoulet, and Janvry, 2000, Bellemare and Barrett, 2006), as well as how they choose between trader pick-up and market delivery when selling their products (Fafchamps and Hill, 2005). A common feature of these studies is that they focus on transportation costs as the main determinant in marketing decisions. One reason for this is that transportation costs are known to be very high in sub-Saharan Africa 1 making them a critical component in a farmer's marketing decisions. Information about market prices is another key determinant. Yet, farmers usually lack information about current market prices because of villages' remoteness and poor communications with marketplaces. When analyzing the role of transaction costs in the farmer's decision to sell to the trader rather than at the market, Fafchamps and Hill (2005) assume that the farmer must choose between receiving a lower price at the farm gate and receiving a higher price at the market yet incurring a transaction cost. The fact that the farmer does not have the necessary price information to engage in optimal trade or arbitrage is relatively poorly investigated. Now that most African farmers have the opportunity to use mobile phones for marketing purposes (Aker and Mbiti, 2010, Goyal and González-Velosa, 2012), a relevant research question would seek to better understand of how price information affects bargaining and the balance of power in the farmer-trader relationship.

\footnotetext{
${ }^{1}$ Recent studies indicate that transportation costs are much higher in sub-Saharan Africa than in other regions (Teravaninthorn and Raballand, 2009). It has also been noted that transportation costs over short distances, for example, from the farm to the local market, are much higher than long-distance transportation costs, presumably because the vehicles are smaller and road quality is poorer (World Bank 2009). In addition, it appears that West African countries often have a relatively well-connected road network compared to East Africa (Dorosh, Wang, You, and Schmidt 2010).
} 
While in 1999 only 10 percent of African people had mobile phone coverage, by 2008 over 65 percent of the population had access to this service. It is often argued that mobile technology is likely to considerably reduce the search costs faced by farmers. With mobile phones, farmers obtain price information for the cost of sending a text message or making a call. This should cause traders visiting farmers at the farm gate to raise the price they are willing to pay for farmer products, an outcome which would result in a welfare transfer from traders to farmers. This accounts for why, along with the Information and Communication Technology (ICT) boom, Market Information Services (MIS) working through mobile phone networks have emerged in some developing countries. These MIS are provided by private companies from ICT sectors such as mobile network operators or software developers, and sometimes by governments. They offer their users market information services, such as SMS alerts on current market prices.2 In Ghana, an Accra-based private company has operated a MIS called Esoko since 2008. This new generation of MIS marks an advancement over previous services $s^{3}$ because it provides users customized and detailed price information on a weekly basis (USAID, 2010). This article seeks to understand how MIS can lead to farmers receiving higher prices for their agricultural products.

We begin our study by modeling the bargaining interactions between a farmer and a trader. Related to the work of Fafchamps and Minten (2012), the question we aim to tackle here is: how much would an informed farmer receive in terms of price gain compared to a situation in which he was uninformed, having no price information? Our model describes a two-player, two-period, offer-offer schema with asymmetric information. We set the assumptions of the model based on observations from our field work as well as the literature. The bargain between the farmer and the trader occurs at the farm gate in a finite sequence of two periods over the course of a day, reflecting the fact that the trader who visits the community in the morning has the opportunity to stop again in the afternoon on the way back. The bargaining procedure is modeled as a sequential game: the trader always begins the negotiation by making an offer, which the farmer either accepts or rejects. The farmer does not know the district market price unless he subscribes to the MIS, while the trader is always fully informed. When negotiation fails, the trader seeks another farmer while the first farmer travels to the

\footnotetext{
${ }^{2}$ There are several examples of companies providing SMS-based market information services in developing countries: Manobi in Senegal, CellBazaar in Bangladesh, KACE in Kenya, and Reuters Market Light in India.

${ }^{3}$ During 1980s, MIS in Africa were centrally managed by government departments or projects, and were mainly aid-funded. Such MIS operated primarily through information boards or radio programs. This first generation of MIS often faced financial and technical difficulties which undermined the proper functioning of the system, affecting information reliability and timeliness.
} 
district market to sell his products; here we assume that a lack of storage space compels him to sell (Al-Hassan, Dorward, and Poulton, 1999). The current market price is exogenous to the players and may be high or low. The total amount of agricultural products supplied each year is uncertain due to uncontrollable exogenous elements such as weather (Moschini and Hennessy, 2001). When the farmer does not subscribe to the MIS, he assigns a probability to each possible state of the market price. Finally, in line with previous studies, traveling to the market is costlier for the farmer than for the trader. Indeed, in our study area, farmers must usually walk or cycle as a means of transportation. While some may afford to hire a private transport as some traders do, this practice was reported by none of farmers interviewed in our sample. They may also make use of public transportation, carrying along their bag of maize on a tro-tro $4^{4}$ however this was not reported as a common practice either. In contrast, the trader transports the products in a cost-efficient fashion, as he owns his own pick-up truck.

We solve the game by backward induction and compare the equilibriums reached with and without MIS. If the market price is high, the model predicts that the individual gain to the farmer from being informed is positive. The reason for this is that the uninformed farmer assigns a non-zero probability to the low-price state, which the trader exploits by offering a low price. This does not occur when the farmer is informed, as it forces the trader to make higher offers to secure the deal. Symmetrically, if the market price is low, the model predicts that the individual gain for the farmer from being informed is negative. This is because the uninformed farmer assigns a non-zero probability to the high-price state while the market price is actually low. In order to secure the deal, the trader is forced to offer a higher price compared to the situation in which the farmer is informed. In this case, asymmetric information can even lead to a deal failure as soon as the profitability condition of the trader no longer holds. Such a situation never occurs when both agents are informed.

We test the model's prediction that information results in positive individual gain for the farmer using original survey data collected in the Northern region of Ghana after the crop season 2009-2010, a year in which the prices of agricultural products were higher than in previous years (see Figure $\mathrm{x}$ ). Our study examines the causal effect of a mobile MIS-based program on farmers' marketing performances in Northern Ghana. We thus add new empirical results to the growing literature on the impact of mobile-based MIS's impact on farmers. We apply the difference-in-difference matching estimator to our data and find that farmers who have access to a mobile-based MIS received significantly higher

\footnotetext{
${ }^{4}$ In Ghana, tro-tros are minivans that can transport up to twenty passengers.
} 
prices for maize and groundnuts during the crop season 2008-2009: about $12.7 \%$ more for maize and 9.7\% more for groundnuts than what they would have received had they not participated in the MIS program. Such results suggest that the theoretical conditions for successful farmer use of MIS may be satisfied in the field.

The empirical literature that deals with the impact of MIS on economic development in poor countries can be divided into two categories. Papers of the first category analyze how MIS improves spatial arbitrage, i.e. welfare gains. To our knowledge, the most cited study on the topic is Jensen (2007). Jensen studies fisheries in India, where fishermen at sea are unable to observe prices in coastal markets. Fishermen sell their catch almost exclusively in their local market due to high transportation costs and nonexistent storage capacity. This induces price gaps across markets in excess of transportation costs, resulting in an inefficient welfare state since fish supply varies across markets. The author shows that the introduction of mobile phone service between 1997 and 2001 led to a considerable reduction in fish market price dispersion, the complete elimination of waste, and near-perfect adherence to the Law of One Price.

The second category is comprised of papers concerned with the impact of MIS on surplus sharing. Similar to our research question, these papers study the impact of information on farmers' bargaining power. In the case of a large private buyer of soybeans in India who invested in Internet applications that allow farmers to access market price information from Web kiosks, Goyal (2010) shows that the introduction of the kiosks lead to a 1-3\% increase in farmer prices and a $33 \%$ increase in profit. In this framework, farmers initially sold their soybeans in local wholesale markets to traders who possessed price information across markets, while the farmers did not. This analysis thus highlights the pure market power effect, by which price information simply increases competition without any change in net welfare gain. Svensson and Yanagizawa (2009) address the market power issue more directly by estimating the impact of a radio-based MIS on Ugandan farmers. They show that access to market information strongly improves farmers' bargaining power at the farm gate. Specifically, having access to a radio in districts where the MIS project was launched is associated with a 15 percent higher farm-gate price. To our knowledge, the first evaluation of a mobile-based MIS has been conducted recently by Fafchamps and Minten (2012). Running a randomized controlled trial to test whether Indian farmers who are MIS users obtain higher prices for their agricultural output, they find a zero impact. However, as the authors underline in their conclusion, larger impacts are possible in other contexts, in particular in less competitive and more segmented markets where farmers sell a 
substantial share of their produce. Accordingly, another contribution of our paper is to provide one of the first impact evaluations of a mobile-based MIS in an African context. The remainder of the paper is organized as follows. First, we model bargaining interactions between a farmer and a trader aiming to reach a deal at the farm gate. Second, we present the data used for the empirical analysis. Finally, we present the results of the econometric analysis and our conclusions.

\section{The model}

\subsection{Preliminaries}

We consider the bargaining of an agricultural transaction between a farmer and a trader. The farmer, denoted by subscript $F$, produces an agricultural good. He admits limited storage capacity and can either sell his production at the farmgate or at the market, which can be the nearest market, an assembly market or a more distant market such as the district market. Traveling to the market is costlier for the farmer than for the trader. Indeed farmers must usually walk or cycle, while the trader transports products using a pick-up truck. Some farmers may afford to hire a private transport, as some traders do, while others make use of public transportation, carrying along their bag of maize on a tro-tro minivan. However neither of these means is reported asa common practice in our study area. We denote $c$ the transportation cost incurred by a farmer when traveling to the market, and $m$ the transportation cost incurred by the trader, with $m<c$. The trader, formally denoted by subscript $T$, buys agricultural goods from the farmer at the farm gate and then sells these goods at the market. Note that we do not consider any bargaining over the quantities sold as do Svensson and Yanagizawa-Drott (2010). Without loss of generality, the price we refer to in the model is the price for buying the entire amount of product offered by the farmer. We suppose there is no limit on the quantity that can be bought from a single farmer 5 We denote the market price as $p^{m}$ and we assume that, due to transportation and transaction costs, this price is necessarily higher than the farmgate price $p$. As for the farmer, we assume the trader expects the transaction to be profitable, meaning that he accepts a deal if it covers his transportation cost 6

\footnotetext{
${ }^{5}$ In practice, the trader may well refuse a portion of the products in the last community he visited, but we ignore this particular situation.

${ }^{6}$ Note that we can also consider that the trader accepts any profitable deal such that it covers his transportation costs as well as an additional premium he expects to receive from the deal. Adding this premium in the model is straightforward and the reader interested in this interpretation may consider that $m$ denotes the transportation cost of the trader plus this premium.
} 
The bargaining between the two parties takes place at the meeting point close to the farm and because, by assumption $p^{m} \geq p+m$ and $m<c$, a Pareto improving agreement always exists for the two players. Though the two agents share a common interest to make a deal, they have conflicting ideas over how to make it. While the trader prefers buying at the lowest possible price, the farmer prefers to sell at the highest possible one. In other words, the two agents conflict over the price $p$ they seek agreement upon and therefore over how to share the rent.

We now look at the variables that may affect price $p$ during bargaining. First, we consider the farmer's production cost. By assumption, a farmer never sells goods at a lower price than his cost. Producing and selling crops ought to be profitable, and the farmer accordingly has a reservation price which we denote $s$. By assumption, we consider that $s \leq p^{m}-m$, meaning that we assume a profitable deal between the farmer and the trader does exist. Second, we assume the market price to be exogenous to our model, meaning that the success or the failure of negotiations as well as the terms of the transaction do not affect it. Conversely, the market price $p^{m}$ is a key determinant of the farm gate price as it delineates the trader's transaction possibilities. Third, the bigger the gap between $m$ and $c$, the larger the set of profitable transactions. The fourth variable to be considered is the relative bargaining power of the two agents. Bargaining skills and the existence of credible threats to end negotiations may affect the bargained price. Finally, both agents are subject to impatience and prefer an immediate deal to a postponed deal. We set a discount factor $\delta$ to measure this impatience, where $\delta \in[0,1]$. The lower this factor, the more impatient and the lower the utility due to a transaction delay.

Formally, the objective functions of two agents who meet at the community market may be written as:

$$
\left\{\begin{array}{c}
U_{T}(p, t)=\delta_{T}^{t-1}\left[p^{m}-m-p_{t}\right] \\
U_{F}(p, t)=\delta_{F}^{t-1}\left[p_{t}-s\right]
\end{array}\right.
$$

By assumption, the larger the trader's net benefit $p^{m}-m-p_{t}$ from making a deal, and the faster this deal is achieved, the greater the trader's utility. Conversely, the larger the price obtained and the lower the production cost, the greater the farmer's utility. Note that all variables are exogenously set besides $p_{t}$. 


\subsection{Strategies and information structure}

We suppose that the bargaining between the two agents takes place in a finite sequence of two periods within a day. Although a general model with $n$ periods might be desirable in theory, we reject this feature because the bargaining we study does eventually occur in a limited number of periods.7 The trader visits a community twice a day on his trip. He passes by each village on his round-trip journey and may stop again on his way back if his truck has not been filled.

The trader can make several deals at the same meeting point but we assume that all negotiations are independent from each other. Indeed, the price one farmer receives does not affect the price received by the next farmer because, as we shall see, the trader makes offers based on parameters that are specific to each farmer.

We suppose that the farmer and the trader meet once in the morning and once in the afternoon. In accordance with qualitative evidence from field, the trader always begins the negotiation by making an offer. The farmer can then either accept or reject this offer. If he accepts, the two agents make a deal and the trader gives $p_{1}$ to the farmer for buying his entire production. If $p_{1}$ is insufficient, the farmer may reject the offer. By assumption, the farmer does not make a counter offer, and rejection in the first period means that the bargain is postponed until the afternoon. 8 In this last case, the farmer incurs the additional cost $c$ but he will benefit from a higher price $p^{m}$. Additionally, his utility will be discounted because he will not be able to reach the market immediately.

When the bargain is postponed, the utilities of the two agents are discounted according to their respective discount rates. Discounting is particularly relevant for farmers. Those who are more isolated are particularly afraid of missing opportunities to sell their products and may therefore be more impatient, displaying a discount factor that may converge toward zero.

When a second bargaining period occurs, the trader makes a new offer. Again the farmer can either accept or reject this offer. If the offer is accepted, the production is sold at price $p_{2}$. If the offer is rejected, the negotiation between the two agents ends and the farmer then travels to the market himself. He incurs the transportation cost $c(c>m)$ but sells his products at price $p^{m}$. The trader in

\footnotetext{
${ }^{7}$ This assumption is made without loss of generality given that, in our setting, considering two periods allows for a complete characterization of the equilibrium set. Note that this is not the case in most bargaining games with incomplete information, where more periods involves more equilibria. Multiplicity arises because perfect Bayesian equilibrium imposes no restrictions on players' beliefs following out-of-equilibrium moves. It follows that considering more periods translates into using more restrictive equilibrium notions, as in Sobel and Takahashi (1983) and Rubinstein (1985). In our setting, this is not the case because, as we shall see, there is no possible revision of the probabilities from one period to the other.

${ }^{8}$ Note that the negotiation may also end if the trader does not stop on his way back. In this case, the farmer will need to sell his products at the market himself.
} 
this case seeks another seller. Because of additional transportation and bargaining costs, we assume that the trader attempts to fill his truck as quickly as possible and is inclined to make any profitable deal.

The game we examine is depicted in Figure 1. According to exogenous elements like weather and the demand curve, the market price can be high $\left(p^{m+}\right)$ or low $\left(p^{m-}\right.$, ) with $p^{m+}>p^{m-}>0$. Market price variability (namely the low-price state and the high-price state) refers to inter-annual variability. One could argue that farmers may sell their products twice within a crop season, with one transaction at the beginning of the marketing season when prices are low and another one during the lean season when prices are higher. In this scenario, market price variability should be understood as intra-annual variability. However, the fact that the farmer may ignore the state of the market within a crop year seems unrealistic to us. We thus opt for the inter-annual variability setting.

In the absence of price information, the trader knows $p^{m}$ and the farmer does not. In the first period, he makes an offer $p_{1}$. If the farmer accepts, the bargaining ends and the payoffs of agents are then respectively $U_{T}\left(p_{1}, 1\right)=p^{m}-m-p_{1}$ and $U_{F}\left(p_{1}, 1\right)=p_{1}-s$. The trader never makes an offer such that $U_{T}\left(p_{1}, 1\right) \leq 0$. If the farmer rejects the offer, he can either wait for the trader's second period offer or go to the market by himself. In this last case, the farmer receives $U_{F}\left(p_{1}, 1\right)=\delta_{F}\left(p^{m}-s-c\right)$. Else, we assume the bargaining continues in the afternoon and the trader makes a new offer $p_{2}$. If agreement is reached in the second period, the payoffs to the agents are $U_{T}\left(p_{2}, 2\right)=\delta_{T}\left[p^{m}-m-p_{2}\right]$ and $U_{F}\left(p_{2}, 2\right)=\delta_{F}\left[p_{2}-s\right]$. By definition, for a deal to be possible, we should have $p_{t}$ such that $s \leq p_{t} \leq p^{m}-$ mmeaning that offers must allow both agents to at least cover their reservation prices. If bargaining ends in disagreement, the farmer sells his products at the market while the trader attempts to make a deal with another farmer. Payoffs are respectively $U_{F}($ fail $)=\delta_{F}\left[p^{m}-s-c\right]$ and $U_{T}(f a i l)=0$. We assume this is the worst possible outcome, and it implies that no agent has an incentive to intentionally seek disagreement.

In the case where the farmer does not know the market price $p^{m}$, we assume that the farmer assigns a probability to types $p^{m+}$ and $p^{m-}$ based on previous crop seasons he has experienced. This probability is common knowledge, meaning that the trader is aware of it. We write $\phi_{t}$ to denote the probability that at period $t$, market price is high and $1-\phi_{t}$ to denote the probability that market price is low. In the second period, the probability $\phi_{2}\left(p_{1}\right)$ is conditional on the fact that, in the first period, the trader offered a price $p_{1}$ which the farmer rejected. At period $t$, the farmer expects the market price to be $\phi_{t} p^{m+}+\left(1-\phi_{t}\right) p^{m-}$. 
The action set of the trader corresponds to all eligible offers making the deal profitable. We denote this by $\digamma_{T}$ which is the set of feasible prices the trader can offer, $\digamma_{T} \in\left[p^{m}-m, \infty[\right.$. A pure strategy for the trader consists of two actions $\left(p_{1}, p_{2}().\right)$ where $p_{1} \in \digamma_{T}$ is the first period offer and $p_{2}(.) \in \digamma_{T}$ is the second period offer, conditional on $p_{1}$ being rejected. The action set of the farmer is $\digamma_{F}=\{a, r\}$, where $a$ denotes acceptance and $r$ denotes rejection of the offer. A pure strategy for the farmer is a couple of actions $\left(F_{1}(),. F_{2}().\right)$ where $F_{1} \in \digamma_{F}$ is the best reply to the offer $p_{1}$ at the first period and $F_{2} \in \digamma_{F}$ is the best reply to the offer $p_{2}$ at the second period, conditional on the offer being rejected in the first period.

\section{How does MIS affect bargained prices?}

Bargained price with MIS We answer this question by first considering the case where the farmer subscribes to MIS. Both agents are perfectly informed, and this is common knowledge. For the sake of simplicity, we ignore the subscription fee and assume the service is free $9^{9}$ As usual, we solve the problem by backward induction. Focusing on the scenario in which a price $p$ exists such that the reservation prices of the two agents are fulfilled, we have:

$$
s \leq p \leq p^{m}-m
$$

The farmer's second period equilibrium strategy is easily computed. He accepts offer $p_{2}$ if and only if $p_{2}$ equals at least $p^{m}-c$. The trader's second period price maximizes his second period payoff given the farmer's second period strategy. He offers $p_{2}=p^{m}-c$, which will be accepted. We then consider the strategy of the farmer in the first period. In order to maximize his utility, he should accept any offer $p_{1} \geq \delta_{F}\left[p^{m}-c\right]+\left(1-\delta_{F}\right) s$. The trader therefore offers:

$$
p_{1}=\delta_{F}\left[p^{m}-c\right]+\left(1-\delta_{F}\right) s
$$

which the farmer accepts immediately.

\footnotetext{
${ }^{9}$ Note that this is actually the case in the data we collected.
} 
We deduce that when farmers are perfectly informed about the market price and when a profitable deal exists between the farmer and the trader, there is a unique subgame perfect equilibrium:

Equilibrium with MIS.Given the model parameters, a unique subgame perfect equilibrium exists:

- The trader offers $p_{1}=\delta_{F}\left[p^{m}-c\right]+\left(1-\delta_{F}\right) s$ and the farmer accepts it immediately.

Bargained price without MIS Solving the game with incomplete information involves the use of perfect Bayesian equilibrium. By definition, perfect Bayesian equilibrium requires that both agents play their best response given uncertainty, which means that the optimal choices depend on agents' beliefs. We first study the second period game when payoffs are not discounted. Given that the trader always offers a price lower than $p^{m}-m$, agreement is necessarily welfare improving for him.

When information is incomplete, the farmer accepts offer $p_{2}$ if it is a best reply given the subjective probability $\phi$. As shown by Ausubel, Cramton, and Deneckere (2002), because the fully informed agent is making the offers, there is no possible revision of the probability distribution from one period to the other at the equilibrium, $\phi_{1}=\phi_{2}=\phi$. The trader is perfectly informed and, given $\phi$, makes the minimal offer that is always accepted by the farmer: $p_{2}=\phi p^{m+}+(1-\phi) p^{m-}-c$. Accounting for price uncertainty, the farmer expects to do as well as he would if he went to the market himself. In other words, he is willing to let the trader capture the benefits corresponding to the gap between their respective transportation costs.

The trader benefits from uncertainty when $p^{m}=p^{m+}$ but interestingly this is not the case when $p^{m}=p^{m-}$. This is because, when $p^{m}=p^{m-}$, the trader must compensate for the optimistic expectations of the farmer in order to secure a deal. Because the farmer believes the market price is high with a positive probability, he is willing to take the risk of going himself to the market if the trader's offer is too low. In order to avoid this situation, the trader concedes a share of his rent to the farmer. Although a Pareto improving agreement exists, the negotiation may however fail. To illustrate this, let us recall that if the deal fails, the trader gets a zero payoff from this transaction failure and seeks to make a deal with another farmer. Therefore, he is willing to offer $p_{2}=\phi p^{m+}+(1-\phi) p^{m-}-c$ if and only if the utility he receives is positive. We deduce that the trader makes offer $p_{2}$ if and only if:

$$
\phi\left(p^{m+}-p^{m-}\right) \leq c-m
$$

Else, he may make an offer such that $U_{T} \geqslant 0$ but this offer will be always rejected by the farmer. 
The two agents here end up in a worse situation. We deduce that uncertainty may collapse the agreement when $p^{m}=p^{m-}$ if the leeway between transportation costs is relatively small, if the probability $\phi$ is high, or if the price volatility is high. In such cases, the farmer rejects any offer that could possibly be made by the trader because he expects to get a higher payoff by selling his products at the market himself. It follows that, in the one-period game, if $\phi\left(p^{m+}-p^{m-}\right)>c-m$, there is no offer made by the trader that the farmer accepts.

We now consider the two period game and examine the strategy of the agents in the first period. If $\phi\left(p^{m+}-p^{m-}\right) \leq c-m$, meaning that if sufficient margins exist for the trader to secure a profitable deal, he always offers:

$$
p_{1}=\delta_{F}\left[\phi p^{m+}+(1-\phi) p^{m-}-c\right]+\left(1-\delta_{F}\right) s
$$

whenever $p^{m}=p^{m+}$ or $p^{m}=p^{m-}$. The farmer always accepts this offer. Conversely, if $\phi\left(p^{m+}-\right.$ $\left.p^{m-}\right)>c-m$, the probability distribution and the volatility of prices are such that the differential of transportation costs between the two agents is too small for a deal to be mutually accepted. In this case, the trader either makes an offer which is always rejected by the farmer, or he abandons the bargain and seeks another farmer. This is a negotiation failure. We deduce that in the bargaining game with incomplete information, there is a unique perfect Bayesian equilibrium:

Equilibrium without MIS. Given the model parameters, a unique perfect Bayesian equilibrium exists:

- If $\phi\left(p^{m+}-p^{m-}\right)>c-m$, we have a market failure: no profitable offer made by the trader can be accepted by the farmer;

- If $\phi\left(p^{m+}-p^{m-}\right) \leq c-m$, the trader offers $p_{1}=\delta_{F}\left[\phi p^{m+}+(1-\phi) p^{m-}-c\right]+\left(1-\delta_{F}\right)$ s and the farmer accepts it immediately.

Remark that the asymmetric information is at the advantage of the trader, who organizes the course of the bargain. The offer scheme is particularly important in producing these results because the sequentiality of periods cannot be used by the farmer to reveal information. In no case can the farmer strategically reject an offer in order to determine whether the market price is $p^{m+}$ or $p^{m-}$. Allowing the farmer to make offers would give him more bargaining power and lead to another rentsharing equilibrium. In the current setting, the trader makes offers that compensate the farmer for 
his production costs (i.e. his reservation price), considering the cost he would incur if he were to sell his products on the market. The farmer's sole protection is this outside option that warrants him a better deal (i.e. without it, the trader would offer a price which would cover $s$ ). This is the only threat the farmer can use in order to capture a share of the rent. Notice that offers are independent of the trader's characteristics.

MIS versus no MIS Comparing equilibriums with and without subscription to MIS allows us to derive two principal insights. A first insight regards the impact of information on the occurrence of a market failure. Although in our setting a Pareto improving deal always exists, asymmetric information about the market price may well lead the two agents to a negotiation failure. In this case, the trader loses his time and gets a zero payoff, and the farmer goes to the market by his own means, ending up in a worse situation than the one he would have been in by accepting the deal.

Result 1. MIS allows for avoiding a possible market failure. When $\phi\left(p^{m+}-p^{m-}\right)>c-m$ and the market price is low, the uninformed farmer rejects any Pareto improving deal the trader can possibly offer. Subscribing to MIS solves this inefficiency and insures that any profitable deal will be achieved.

This result is derived from condition (1). Without MIS, a deal between the two agents is feasible if and only if $\phi\left(p^{m+}-p^{m-}\right) \leq c-m$. As soon as $\phi$ is larger than $\frac{c-m}{p^{m+}-p^{m-}}$, the trader is not able to make an offer that is profitable for himself as well as acceptable to the farmer. This market failure is a consequence of the farmer's uncertainty about the market price. As soon as the transportation cost differential $c-m$ is not sufficient to compensate for the farmer's positive expectations about the market price, the failure is likely to cause each agent to end up with their outside option, the worst possible outcome for both. Wrong expectations about the market price will be all the more likely when inter-annual price variability is high, making information very valuable in environments where prices vary significantly from one year to the other.

A second insight regards the impact of MIS over the prices bargained. For readability purposes, we call $p^{1}$ and $p^{0}$ the prices offered by the trader when the farmer is informed and uninformed, respectively, about the value of the market price. Focusing on the case where $\phi\left(p^{m+}-p^{m-}\right) \leq$ $c-m$, which is the condition for reaching a deal despite price uncertainty, we know that if the farmer does not subscribe to MIS, whether the market price is high or low, the trader offers $p^{0}=$ 
$\delta_{F}\left[\phi p^{m+}+(1-\phi) p^{m-}-c\right]+\left(1-\delta_{F}\right) s$. When the farmer subscribes to MIS, the trader offers $p^{1}=$ $\delta_{F}\left[p^{m+}-c\right]+\left(1-\delta_{F}\right) s$ if the market price is high, and $p^{1}=\delta_{F}\left[p^{m-}-c\right]+\left(1-\delta_{F}\right) s$ if the market price is low. The farmer always accepts the offer immediately.

In order to make theoretical predictions about the impact of MIS on market prices, consider the mapping $f$ such that $f=p^{1}-p^{0}$. When market price is high, we have:

$$
f^{+}=\delta_{F}(1-\phi)\left(p^{m+}-p^{m-}\right)
$$

and when market price is low, we have:

$$
f^{-}=-\delta_{F} \phi\left(p^{m+}-p^{m-}\right)
$$

We deduce the following result:

Result 2. Farmer's use of MIS is beneficial when market price is high and detrimental when market price is low.

An important insight is that inter-annual price variability is the key factor in determining whether MIS has a positive or negative impact on the farmer. When market prices are high, farmers benefit from obtaining information about market prices because it impedes the trader from taking advantage of their ignorance about the state of the market. Based on experience from past years, farmers assign a positive probability of $(1-\phi)$ to the low price occurrence, and the trader exploits this wrong expectation in order to capture an additional share $f^{+}$of the surplus. The trader offers a price $p^{0}<p^{1}$ and the farmer accepts this offer because he is not aware that he could obtain a higher utility by going to the market himself. This is the standard mechanism by which the trader is able to take advantage of the farmer's ignorance of market prices. When market price is low, price uncertainty works in the opposite way and allows for the farmer to capture an additional share $f^{-}$of the surplus. Because the farmer assigns a probability of $\phi$ to the high market price state, the trader has no other choice than to concede a share of his surplus in order to secure the deal. Notice that the variability of prices affects the magnitude of $f$. The bigger $p^{m+}-p^{m-}$, the bigger $|f|$. If variability is high, a farmer's uncertainty about market prices is also high, making information even more beneficial when market price is high and detrimental when market price is low. Notice also that $p^{0}$ increases with $\phi$. Said differently, when the probability assigned by the farmer gets closer to one, the farmer benefits 
less from price information.

Finally remark that adding risk aversion to farmer's preferences increases the positive impact from MIS. Considering a risk premium $\pi$ to farmer's utility as in Fafchamps and Minten (2012) translates in our setting as increasing the transportation cost of the uninformed farmer by this premium. Knowing that the farmer is risk averse, the trader makes an offer accounting for it. Formally, it follows that adding risk aversion to our model does not affect $p^{1}$ but lowers $p^{0}$ such that $p^{0}=\delta_{F}\left[\phi p^{m+}+(1-\phi) p^{m-}-c-\pi\right]+\left(1-\delta_{F}\right) s$. The direct consequence is that the impact of MIS is larger in high-price years and may be positive in low-price years.

\section{Empirical framework}

We test model's prediction that information results in positive individual gain for the farmer using original survey data collected in the Northern region of Ghana after the marketing season 2009-2010 (a high-price year), as illustrated in Figure 2. Specifically, we look at the causal effect of a mobile MIS-based program on farmers' marketing performances.

\subsection{The program and the data}

Esoko (formerly TradeNet) began in 2005 with funding from USAID 10 In order to promote their service, Esoko have worked with a partnering NGO called SEND West Africa since 2008. SEND West Africa facilitated the acquisition of mobile phones for 500 farmers in the Northern Ghana and trained them on how to make sense out of Esoko automatic price alerts. The NGO initiated the Eastern Corridor Agro-Information Center (ECAMIC) project by creating cooperative farmer groups within communities in the Northern Ghana districts where SEND had already run several development projects for many years 11 They first facilitated the acquisition of mobile phones for 200 farmers by subsidizing cell phone purchases and paying for a one-year subscription to Esoko services. These first Esoko users began to receive SMS alerts on district market prices in June 2009. In practice, Esoko enumerators collect wholesale prices on local and distant markets on a weekly basis and download them onto the platform so that, a few days after the fact, subscribers receive price information on the most often quoted price for the products and the markets of their choice. ECAMIC cooperatives

\footnotetext{
${ }^{10}$ Esoko is a for-profit private company with private investors such as IFC from the World Bank group and the SEDF foundation.

${ }^{11}$ These projects aimed to tackle issues related to the Liberian refugees in Ghana.
} 
generated lists of farmers who could be involved in the ECAMIC project. These eligible farmers must have been active members of the cooperative and must have owned an account at the credit union. At the end of 2009, SEND found another funder (Prestat Chocolate), which allowed them to expand the ECAMIC project. An additional wave of Esoko users were trained and began to receive SMS alerts from Esoko in May-June 2010. The first-wave participants enjoyed a fully-subsidized subscription for a second time in 2010. The project ended in May 2011. The Northern region of Ghana covers about $30 \%$ of the country (MoFA, 2011). It is part of the agro-ecological zone called Guinea Savannah, where the wet season usually starts in April-May and ends in September-October, when the harvesting of the main season crops takes place. The total quantity of maize marketed annually in Ghana is widely reported by maize market stakeholders to be about one million MT (USAID, 2012). Maize is produced predominantly by smallholders who consume a significant share of it as a primary staple food (USAID, 2012). Most farmers intercrop maize with groundnut12 The survey covers a total of 600 farmers, surveyed individually during July 2010. It is a recall survey about what happened during the 2009 marketing season. For the purposes of the analysis, a number of questions also focuses on the previous marketing season. The surveyed farmers are smallholders who produce mainly maize, yam, groundnut, and cassava over areas of about 15 acres. The study area covers the districts of East Gonja, Krachi West, Nanumba North and South (Figure 3). Since practical constraints of the project did not allow us to survey more than 600 farmers, we surveyed all direct users (a total number of 196), obtained from the Ecamic list of participants, 200 indirect users ${ }^{13}$ randomly selected from the list of second-wave participants (200 out of 300), and 200 non-users who did not benefit from the ECAMIC project, since they were not members of ECAMIC communities (though they lived in the same districts). Since the entire population of non-users was quite large, we focused on composing our sample from communities that resembled the users' communities in two respects: they were the same distance from the nearest local markets and they had a similar percentage of literate farmers. In practice, once the villages have been selected on the basis of the geographical criteria, the enumerators went door-to-door in a random manner until they obtained the number of literate respondents that had been set for each community: ${ }^{14}$

\footnotetext{
${ }^{12}$ In most densely populated parts of the zone, crop residues of legumes (especially groundnut) are sold or traded for other goods (Karbo and Agyare, 2002).

${ }^{13}$ We call these indirect users because at the time we surveyed the second-wave participants, they had recently been trained and set up for automatic SMS alerts on prices. Thus they were not actively participating in the program during the 2009 marketing season, though they lived in the same neighborhoods as other users.

${ }^{14}$ We surveyed a proportion of non-user literate farmers that was close to the proportion of literate farmers in users' groups. Given that an average of $60 \%$ of farmers are literate in users' groups (120 among 200), we also surveyed 120
} 
Table 2 and 3 describes information collected in the survey on the characteristics of the farmers and of their main transaction for maize and groundnut at the first point of sale, which is the meeting point where all of the farmers from the local community meet the trader who visits the village $\sqrt{15}$ The main transactions happen to occur in the post-harvest period because farmers do not have any place where they are able to store their products. Each farmer in the sample grows at least one of these products (maize or groundnuts). The table reports mean values for various farmer characteristics. The average number of hectares of cultivated area is 15 acres. The average non-agricultural income is 600 GHS, although only half of the sample depends solely on agriculture for their income. We observe that the range of prices collected for these products (Table 3 includes aggregate mean values provided by the FAOSTAT or calculated from the Ghana Living Standards Survey data (2006): around 45 GHS for a maxi bag $(100 \mathrm{~kg})$ of maize and 85 GHS for a maxi bag of groundnuts. The quantity sold as a proportion of the total harvest quantity for each product is on average very large ( $73 \%$ for maize and $87 \%$ for groundnuts). The average distance to the nearest market is $15 \mathrm{~km}$, and the average distance to the district market is $23 \mathrm{~km}$.

\subsection{Identification strategy}

Our parameter of interest is the average gain from the Esoko-based program for the subset of farmers who actually benefited from the program during the 2009-2010 marketing season. This parameter answers the question: how much did informed farmers receive (in terms of a price premium) compared to what they would have received, had they not entered the program? This is the so-called average treatment effect on the treated, defined as $A T T=E\left(p^{1}-p^{0} \mid w=1\right)$, where $p^{1}$ denotes the farmer's outcome in the presence of the Esoko program (the treatment), $p^{0}$ denotes the outcome in the absence of the Esoko program, and $w$ is a dummy which takes on the value of one when the farmer is in the program. We use matching methods to estimate the outcome level of the treated farmer in the unobserved state, namely $E\left(p^{0} \mid w=1\right)$.

The matching approach is widely used when evaluating development programs (Todd, 2008). The main concerns in assessing the impact of development programs are related to the fact that such programs are not offered at random and that participants self-select into them. The crucial issue is

literate farmers in non-user communities. This means that the enumerators went door-to-door in these communities until they obtained 120 literate respondents and 80 non-literate respondents. The "can you read" question in the questionnaire was thus the screening question.

${ }^{15}$ Typically, the trader announces his arrival in the community by honking. 
thus to determine what factors are likely to drive both participation in the Esoko program as well as farmers' marketing performances. Although we did not find qualitative evidence suggesting that the NGO which supported the program had intentionally targeted farmers who marketed larger surpluses or living in more isolated communities, we can reasonably expect that farmers who self-selected into the program felt comfortable using mobile phones and were relatively market-oriented farmers to begin with, though smallholders nonetheless. Moreover, we know that the NGO had been working in this area for a long time, running various projects often involving the same communities. To the best of our knowledge, at least two initiatives of the NGO that run in conjunction with the Esokobased program can be considered confounding factors in our framework. First, participants in the Esoko-based program are also members of a credit union. Second, as members of the NGO, these farmers may also have opportunities to sell their products as a group. We use matching estimators to eliminate selection bias due to farmers' characteristics and possible participation in other programs.

Matching eliminates selection bias due to observable factors $X$ by comparing treated farmers to observationally identical untreated ones (Imbens, 2004). Because, even after conditioning on observables factors $X$, there may be systematic differences between informed and uninformed farmers' outcomes that could lead to a violation of the identification conditions required for matching, we choose to apply the difference-in-difference matching estimator, as defined in Heckman, Ichimura, and Todd (1997). This estimator allows for temporally invariant differences in outcomes between informed farmers and their $X$-matched uninformed counterparts, since at least two observations per individual are available. It requires that $E\left(p_{t}^{0}-p_{t^{\prime}}^{0} \mid X, w=1\right)=E\left(p_{t}^{0}-p_{t^{\prime}}^{0} \mid X, w=0\right)$, meaning that the average difference in $p$ between the two groups must be constant through time in the absence of treatment, in other words, that observationally identical treated and untreated individuals must exhibit the same change in $p$ in the absence of treatment. Applied to our data, this identification strategy consists in comparing the annual change in the outcome of informed farmers with the annual change in the outcome of matched uninformed farmers. We measure annual change as the difference between crop seasons 2008 and 2009 .

Another key assumption for the validity of the DID matching approach is that the treatment received by one farmer does not affect the outcome of another farmer. This assumption is referred to as the Stable-Unit-Treatment-Value-Assumption in the statistics literature (Rubin, 1978). In our framework, the validity of this assumption could be threatened in two ways. First, treated farmers may share Esoko price information with untreated farmers. Second, Esoko price information may 
have market equilibrium effects, affecting outcomes of both informed as well as uninformed farmers. Regarding the first issue, we do expect some information to diffuse between members of the same community, which is why we include the second-wave participants in the treated group as well. On the contrary, spillovers between communities are less likely because communities are somewhat scattered in space, which may cause interactions and informal networks to be weaker across communities. Indeed, our data confirm that spillovers within communities are much larger than spillovers across communities: among 200 non-users living with Esoko-users in the same communities, 190 farmers stated that somebody they know had provided them price information that was obtained from their phone (in all cases, this information provider happened to be an Esoko-user), while among 200 nonusers living in different communities, albeit still in the neighborhood, only 55 farmers stated that they had benefited from such information (the information provider happened to be an Esoko-user in 38 cases out of 55). We thus do not fear the contamination of the control group, since treated and untreated farmers live in separate communities. Regarding the market equilibrium issue, as long as informed farmers do not change the quantity that will be brought to the market (by the trader or by themselves), we should not expect market prices to be altered. However, previous studies in other African countries show that informed treated farmers may actually alter the quantities they sell and/or exert an arbitrage opportunity, thus altering the overall market price on the assembly market and thereby changing the prices paid to farmers in untreated communities Svensson and Yanagizawa-Drott, 2010). We test this assumption in our data and fail to detect a significant change in the sold proportion of the total harvest quantity of informed farmers (see next section).

We use the nearest-neighbor matching estimator (Abadie, Drukker, Herr, and Imbens, 2004), the kernel-based matching estimator, and the local linear matching estimator (Leuven and Sianesi, 2003). The general form of the DID matching estimator is:

$$
E\left(p^{1}-p^{0} \mid w=1\right)=\frac{1}{n 1} \sum_{i \in I_{1} \cap S_{P}}\left(p_{i t}^{1}-p_{i t^{\prime}}^{0}-E\left(p_{i t}^{0}-p_{i t^{\prime}}^{0} \mid w=1, X_{i}\right)\right)
$$

with

$$
E\left(p_{i t}^{0}-p_{i t^{\prime}}^{0} \mid w=1, X_{i}\right)=\sum_{j \in I_{0}} \lambda_{i j}\left(p_{j t}^{0}-p_{j t^{\prime}}^{0}\right)
$$

where $I_{1}$ denotes the group of treated farmers, $I_{0}$ denotes the group of untreated farmers, $n_{1}$ is the number of treated farmers in $I_{1}$. $S_{P}$ denotes the common support, or the subset of treated farmers 
for whom the density of observationally identical untreated farmers is higher than some cut-off level (Todd, 2008). Matching estimators differ in how matched untreated farmers are selected through the matching procedure. This difference is driven by the weights $\lambda_{i j}$ that we assign to potential matches given their characteristics $X$. The nearest-neighbor matching estimator we use in the analysis matches each certified farmer to the four closest uncertified farmers according to the vector $X$. It is important that the covariates $X$ are not affected by the treatment (Imbens, 2004), which is why we use values from 2008-2009, assuming that they will not yet be affected by the program on the exact date that it starts. We apply the matching procedure to the summary statistic $\operatorname{Pr}\left(w_{i}=1 \mid X_{i}\right)$, the so-called propensity score (Rosenbaum and Rubin, 1983). We use the asymptotically-consistent estimator of the variance of the nearest-neighbor matching estimator provided by Abadie and Imbens (2006), and we implement a bootstrap procedure (500 repetitions) to obtain an estimator of the variance of the kernel matching estimator and of the local linear matching estimator.

Another, computationally easier, way to generate an estimate of the ATT is to regress $w$ on $y$, controlling for $X$, by using ordinary least squares. However, in addition to the assumption of linearity, this requires us to assume that the gain associated with the program is constant across $X$, meaning that the impact of the program is the same for all informed farmers. Without any evidence for such assertion, we thus opt for the widely-used matching approach, which does not require specifying the functional form of the outcome equation and relaxes the assumption of constant additive treatment effects across individuals. We nevertheless run linear regressions as a robustness check.

\section{$5 \quad$ Results}

\subsection{Impact of the program on the treated}

We apply the matching procedure to the ECAMIC group of farmers (the treated group) and to the group of farmers who did not benefit from the ECAMIC project (the untreated group). The treated group also includes the group of farmers who entered the program under Prestat funding. Since they entered the program after the marketing season under study, they cannot be considered part of the treated group; however, because they reside in the same communities as ECAMIC farmers, neither can they be considered part of the untreated group because of highly potential spillovers within communities.

Conditional probabilities for participation in the program are computed by estimating a probit 
model where the dependent variable is $w$ and which includes all covariates $X$ as regressors. We include in vector $X$ the farmer's age, his level of education (a dummy which takes on the value of one if the farmer can read), his experience as a farmer (in years), the distance he lives from the nearest market (in $\mathrm{km}$ ), the distance between the community and the district market (in $\mathrm{km}$ ), the farmland (in acres), the total area under cultivation (in acres), the area under cultivation for maize, cassava, groundnut, and yam (in acres), the number of livestock (cattle, goats, pigs, poultry, and sheep), whether or not he owns a radio (a dummy which takes on the value of one if yes), and the total value of his non-agricultural income (in Ghanaian Cedi, GHS).

These propensity scores are first used to define the common support, i.e. the subset of treated farmers for whom the density of untreated farmers with a similar propensity score is high enough. ${ }^{16}$ The graph of the distribution of propensity scores suggests that densities are high enough for a wide range of propensity scores (Figure 4). The matching procedure is considered successful when significant differences of covariates $X$ among the treated and matched-untreated are removed. We test the balancing property following the algorithm proposed by Becker and Ichino (2002) and conclude that it is satisfied 17

Table 4 gives the estimated $A T T$ in terms of price premium for maize and groundnut, the two products for which we have a large enough number of observations. Informed farmers received about 46 GHS for a maxi-bag of maize, which is 5.2 GHS more than the control group. They also received 85 GHS for a maxi-bag of groundnuts, i.e. about 7.5 GHS more than the controls. This means a 12.7\% gain for maize and a $9.7 \%$ gain for groundnuts, compared to a situation without price information.

\subsection{Discussion on selection bias}

The specific context in which the farmers of our sample were offered access to price information requires that we further investigate whether confounding factors drive our estimations. Indeed, treated farmers may also benefit from access to credit via the credit union. In the case where farmers use

\footnotetext{
${ }^{16}$ To do so, we apply the standard procedure as described in Todd (2008): after excluding points for which the estimated density is zero, we exclude an additional small percentage of the remaining points for which the estimated density is positive but very low. Our estimated cut-off density is 0.077 and the trimming level is 0.006 . The final number of treated farmers on the common support is 328 (out of 332).

${ }^{17}$ Becker and Ichino (2002)'s algorithm splits the sample into k equally spaced intervals of the propensity score. Then within each interval, the algorithm tests that the average propensity score of the treated and control units does not differ. If the test fails in one interval, it splits the interval in half and tests again. In our analysis, the final number of blocks is six. This procedure ensures that the mean propensity score is the same for the treated and controls in each block. Results of the test indicate that all covariates are balanced except three (distance between the community, the district market in block five, and two variables of livestock in block six).
} 
credit to buy inputs such as seed and fertilizers, they are more likely to produce higher yields. This may translate to larger transactions and consequently higher prices, since buyers who travel to them reduce transaction costes and may consent to buy at a higher price. If this is true, our estimates would be biased upward. Moreover, farmers may also use credit to buy food or pay school fees. No longer under a liquidity constraint, they would be able to better negotiate prices in this scenario. If this is true, here again our estimates would be biased upward. Data indeed suggest that only a small share of treated farmers declare not having access to credit (14\%), contrary to untreated (47\%), as shown in Table 5. Moreover, it seems that credit is mainly invested in equipment or inputs. We thus control for this potential "credit union effect" using additional covariates when running the matching procedure, namely the total credit used for equipments (in GHS), the total credit used for seeds and fertilizers (in GHS), and the yield level observed in 2009. Finally, our results appear very similar to previous ones (Table 7). We apply the matching estimators to the sold quantity as a proportion of the total harvest quantity for each product and fail to detect any significant impact. Taken together, these results provide some evidence that access to the credit union does not play as a confounding factor in our setting.

Data also suggest that some treated farmers (20\%) mainly sell their produce as a group, while untreated farmers almost never do. This may influence our estimates, again because the traders who travel to the farmers reduce their transaction costs when large quantities are available. We control for this potential "collective marketing effect" by adding a dummy that takes on the value of one in the set of covariates. However, this does not yield different results compared to previous estimates. We take this to be evidence that there is no selection bias driven by a collective marketing effect (Table 8).

\section{Conclusion}

Although the potential for mobile-based MIS in agricultural development seems important, analyses of the conditions for its positive impact on farmers' marketing performances are rather scarce, as are empirical impact evaluations. In this article, we model bargaining interactions between a farmer and a trader and we study how information affects the bargain and the balance of power. We elicit

\footnotetext{
${ }^{18}$ The traders who buy small quantities must bear the cost of sorting and grading each parcel in order to match it with parcels of similar quality goods. They may also have to weigh and re-pack the product and transport it to another market.
} 
conditions for MIS to improve farmers' marketing performances and demonstrate how information affects a farmer's decision to sell at the farm gate rather than at the market. An unexpected result of the model is that providing price information to the farmer allows him to avoid negotiation failure with the trader while Pareto improving deals exist. Regarding cases when deals do occur, the model shows that the impact of price information is positive when the market price is high and negative when the market price is low, an important finding given the high volatility of market prices. Next, we use a quasi-experimental approach relying on survey data about farmers' transactions in Northern Ghana in 2009, a high-price year compared to previous years. We estimate the causal effect of an MIS-based program on farmers' marketing performances and find that farmers who have access to the MIS received significantly higher prices for maize and groundnut: about $12.7 \%$ more for maize and $9.7 \%$ more for groundnuts than what they would have received had they not participated in the program. These results suggest that the theoretical conditions for successful farmer use of MIS may be met in the field. However, it remains unclear whether a $10 \%$ gain in farm gate prices will be an incentive to adopt the MIS technology. Indeed, despite the potential value of information and the low marginal cost of the technology (the cost of sending an SMS message), only a small share of African farmers actually use a mobile-based MIS outside of development programs, for reasons that are not well documented.

Much remains to be done to test all of the predictions of the theoretical model. In particular, it would be useful to collect detailed data on transactions completed at the market due to negotiation failures at the farm gate. Indeed, the data we use only describe the main farm gate transactions, meaning that we are not able to estimate the average impact on informed farmers who travel to the market. Moreover, it would be interesting to investigate a more dynamic framework in which average treatment effects are not constant through time because of traders' strategy adjustments. In particular, we may suppose that if the diffusion of MIS is not uniform, meaning that MIS expands in some communities but not in others, the trader may well adapt to this information landscape. Specifically, he should seek to deal in uninformed communities when the market price is high, because in that case uninformed farmers, who systematically make incorrect estimates of the market price, agree to accept relatively low prices. On the contrary, the trader should visit informed communities when the market price is low, because it allows him to avoid costly negotiation failures. 


\section{References}

Abadie, A., D. Drukker, J. L. Herr, and G. W. Imbens (2004): "Implementing matching estimators for average treatment effects in Stata," Stata Journal, 4(3), 290-311.

Abadie, A., And G. W. Imbens (2006): "Large Sample Properties of Matching Estimators for Average Treatment Effects," Econometrica, 74(1), 235-267.

Aker, J. C., And I. M. Mbiti (2010): "Mobile Phones and Economic Development in Africa," The Journal of Economic Perspectives, 24(3), 207-232.

Al-Hassan, R., A. Dorward, and C. Poulton (1999): "Improving Access to Maize Marketing Opportunities in Remote Areas of Ghana," Discussion paper, University of Ghana Legon, Wye College.

Ausubel, L. M., P. Cramton, and R. J. Deneckere (2002): "Bargaining with incomplete information," in Handbook of Game Theory with Economic Applications, ed. by R. Aumann, and S. Hart, vol. 3 of Handbook of Game Theory with Economic Applications, chap. 50, pp. 1897-1945. Elsevier.

Becker, S. O., AND A. ICHINO (2002): "Estimation of average treatment effects based on propensity scores," Stata Journal, 2(4), 358-377.

Bellemare, M. F., and C. B. Barrett (2006): "An Ordered Tobit Model of Market Participation: Evidence from Kenya and Ethiopia," American Journal of Agricultural Economics, 88(2), 324-337.

Dorosh, P., H.-G. Wang, L. You, and E. Schmidt (2010): "Crop production and road connectivity in Sub-Saharan Africa : a spatial analysis," Policy Research Working Paper Series 5385, The World Bank.

FAfChamps, M., And R. V. Hill (2005): "Selling at the Farmgate or Traveling to Market," American Journal of Agricultural Economics, 87(3), 717-734.

(2008): "Price Transmission and Trader Entry in Domestic Commodity Markets," Economic Development and Cultural Change, 56, 729-766.

Fafchamps, M., And B. Minten (2012): "Impact of SMS-Based Agricultural Information on Indian Farmers," The World Bank Economic Review. 
Goetz, S. J. (1992): "A Selectivity Model of Household Food Marketing Behavior in Sub-Saharan Africa," American Journal of Agricultural Economics, 74(2), pp. 444-452.

Goyal, A. (2010): "Information, Direct Access to Farmers, and Rural Market Performance in Central India," American Economic Journal: Applied Economics, 2(3), 22-45.

Goyal, A., and C. González-Velosa (2012): "Improving Agricultural Productivity and Market Efficiency in Latin America and The Caribbean: How ICTs can Make a Difference?," Lcssd occasional paper series on food prices, Washington D.C. - The Worldbank.

Heckman, J. J., H. Ichimura, and P. E. Todd (1997): "Matching as an Econometric Evaluation Estimator: Evidence from Evaluating a Job Training Programme," Review of Economic Studies, $64(4), 605-54$.

Imbens, G. W. (2004): "Nonparametric Estimation of Average Treatment Effects Under Exogeneity: A Review," The Review of Economics and Statistics, 86(1), 4-29.

Jensen, R. (2007): "The Digital Provide: Information (Technology), Market Performance, and Welfare in the South Indian Fisheries Sector," The Quarterly Journal of Economics, 122(3), 879924.

Jensen, R. T. (2010): "Information, efficiency, and welfare in agricultural markets," Agricultural Economics, 41(s1), 203-216.

Karbo, N., AND W. AgYare (2002): "Crop-livestock systems in northern Ghana," in Improving Crop-Livestock Systems in the Dry Savannas of West and Central Africa, ed. by G. Tarawali, and P. Hiernaux, pp. 112-126.

Key, N., E. Sadoulet, and A. D. Janvry (2000): "Transactions Costs and Agricultural Household Supply Response," American Journal of Agricultural Economics, 82(2), 245-259.

Leuven, E., and B. Sianesi (2003): "PSMATCH2: Stata module to perform full Mahalanobis and propensity score matching, common support graphing, and covariate imbalance testing," Statistical Software Components, Boston College Department of Economics.

MoFA (2011): "Agriculture in Ghana: Facts and figures 2010," Discussion paper, Ministry of Food and Agriculture (MoFA) - Statistics, Research and Information Directorate (SRID). 
Moschini, G., and D. A. Hennessy (2001): "Chapter 2 Uncertainty, risk aversion, and risk management for agricultural producers," in Agricultural Production, ed. by B. L. Gardner, and G. C. Rausser, vol. 1, Part A of Handbook of Agricultural Economics, pp. 88 - 153. Elsevier.

Mérel, P. R., R. J. Sexton, and A. Suzuki (2009): "Optimal Investment in Transportation Infrastructure When Middlemen Have Market Power: A Developing-Country Analysis," American Journal of Agricultural Economics, 91(2), pp. 462-476.

Rosenbaum, P. R., and D. B. Rubin (1983): "The Central Role of the Propensity Score in Observational Studies for Causal Effects," Biometrika, 70(1), 41-55.

Rubin, D. B. (1978): "Bayesian Inference for Causal Effects: The Role of Randomization," The Annals of Statistics, 6(1), 34-58.

Rubinstein, A. (1985): Choice of conjectures in a bargaining game with incomplete informationchap. 6, pp. 99-114. Cambridge University Press.

Sobel, J., And I. Takahashi (1983): "A Multistage Model of Bargaining," Review of Economic Studies, 50(3), 411-26.

Svensson, J., and D. Yanagizawa (2009): "Getting Prices Right: The Impact of the Market Information Service in Uganda," Journal of the European Economic Association, 7(2-3), 435-445.

Svensson, J., And D. Yanagizawa-Drott (2010): "Tuning in the Market Signal: The Impact of Market Price Information on Agricultural Outcomes," Discussion paper.

Teravaninthorn, S., and G. Raballand (2009): "Transport Prices and Costs in Africa : A Review of the Main International Corridors," Discussion paper, The International Bank for Reconstruction and Development / The World Bank.

TodD, P. E. (2008): "Evaluating Social Programs with Endogenous Program Placement and Selection of the Treated," vol. 4, chap. 60, pp. 3847-3894. Elsevier, 1 edn.

USAID (2010): "Using ICT to Provide Agriculture Market Price Information in Africa," Discussion paper, Fostering Agriculture Competitiveness Employing Information Communication Technologies, USAID. 
USAID (2012): "The Market for Maize, Rice, Soy, and Warehousing in Northern Ghana," Discussion paper, the United States Agency for International Development.

World BAnK (2009): "Eastern Africa : A Study of the Regional Maize Market and Marketing Costs," Discussion paper, The International Bank for Reconstruction and Development / The World Bank. 
Table 1: Bargaining outcomes when profitable deals exist

\begin{tabular}{lccc} 
& without MIS & with MIS & $f=p^{1}-p^{0}$ \\
\hline$p^{d}=p^{d+}$ & deal & deal & $f \geq 0$ \\
$p^{d}=p^{d-}$ and $\phi\left(p^{d+}-p^{d-}\right) \leq c-m-k$ & deal & deal & $f \leq 0$ \\
$p^{d}=p^{d-}$ and $\phi\left(p^{d+}-p^{d-}\right)>c-m-k$ & failure & deal & \\
\hline
\end{tabular}

Table 2: Descriptive Statistics on Characteristics of farmers (2008)

\begin{tabular}{llrrrrr}
\hline Variable & Unit & Obs & Mean & Median & Min & Max \\
\hline Age & years & 596 & 41.3 & 40 & 17 & 85 \\
Education & yes $=1$ & 599 & 0.6 & 1 & 0 & 1 \\
Experience & years & 585 & 14.8 & 14 & 1 & 65 \\
Non-agricultural income & GHS/year & 599 & 608.3 & 0 & 0 & 16400 \\
Radio & yes $=1$ & 597 & 0.7 & 1 & 0 & 1 \\
Cattle & number & 599 & 1.7 & 0 & 0 & 112 \\
Goats & number & 599 & 3.6 & 1 & 0 & 40 \\
Pigs & number & 599 & 1.6 & 0 & 0 & 40 \\
Poultry & number & 599 & 12.2 & 10 & 0 & 50 \\
Sheep & number & 599 & 1.5 & 1 & 0 & 39 \\
& & & & & & \\
Size of farmland & acres & 564 & 32.8 & 25 & 2 & 501 \\
Cultivated area & acres & 534 & 14.7 & 12 & 1 & 112 \\
Cassava area & acres & 587 & 3.0 & 1 & 0 & 110 \\
Groundnut area & acres & 597 & 2.2 & 2 & 0 & 188 \\
Maize area & acres & 596 & 5.8 & 2 & 0 & 70 \\
Yam area & acres & 598 & 4.6 & 4 & 0 & 32 \\
Total amount of credit received & GHS & 599 & 205.4 & 70 & 0 & 5000 \\
Total amount of credit used for inputs & GHS & 599 & 173.3 & 50 & 0 & 4880 \\
Purchase of fertilizer for gnuts & GHS & 599 & 29.0 & 0 & 0 & 1000 \\
Purchase of fertilizer for maize & GHS & 599 & 104.8 & 30 & 0 & 4000 \\
\hline
\end{tabular}

Table 3: Descriptive Statistics on Characteristics of Main Transactions (2009)

\begin{tabular}{|c|c|c|c|c|c|c|}
\hline Variable & Unit & Obs & Mean & Median & Min & Max \\
\hline Sold maize as share of total harvested maize & Share & 401 & 0.73 & 0.9 & 0 & 1 \\
\hline Sold gnuts as share of total harvested gnuts & Share & 406 & 0.87 & 0.9 & 0 & 1 \\
\hline Price of maize maxibag & GHS & 369 & 45.1 & 40.0 & 10 & 95 \\
\hline Price of groundnut maxibag & GHS & 246 & 87.7 & 85.0 & 30 & 150 \\
\hline Sale in group & yes $=1$ & 586 & 0.14 & 0 & 0 & 1 \\
\hline Distance to community market & $\mathrm{km}$ & 570 & 15.4 & 13 & 0 & 64 \\
\hline $\begin{array}{l}\text { Distance between community } \\
\text { and district }\end{array}$ & $\mathrm{km}$ & 586 & 23.0 & 19 & 0 & 58 \\
\hline
\end{tabular}


Figure 1: Diagram of the bargaining game

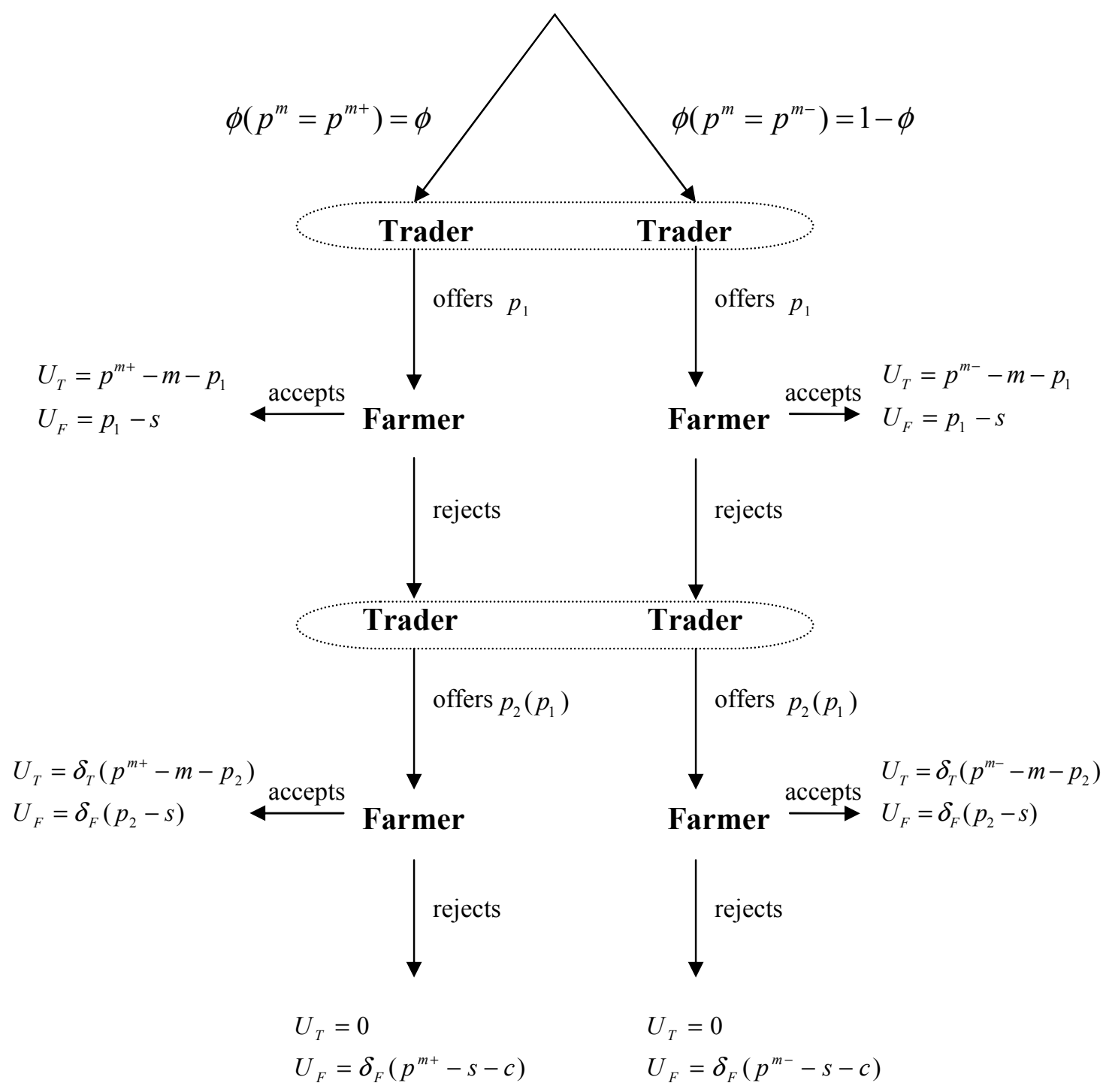


Figure 2: Retail prices of Maize in Tamale (Ghana Cedi/Kg)

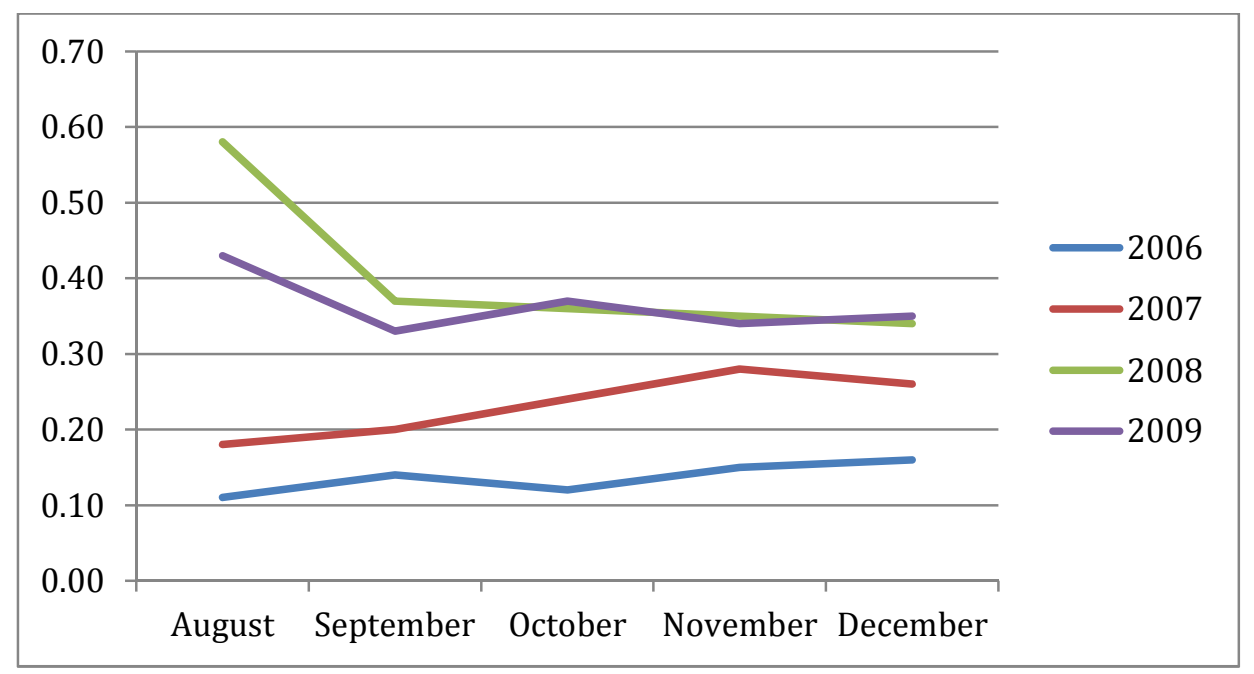

Source: FEWSNET http://www.fews.net/ - provided by FAO GVIEWS Food Price Data and Analysis Tool http://www.fao.org/giews/pricetool/ 
Figure 3: Location of surveyed farmers

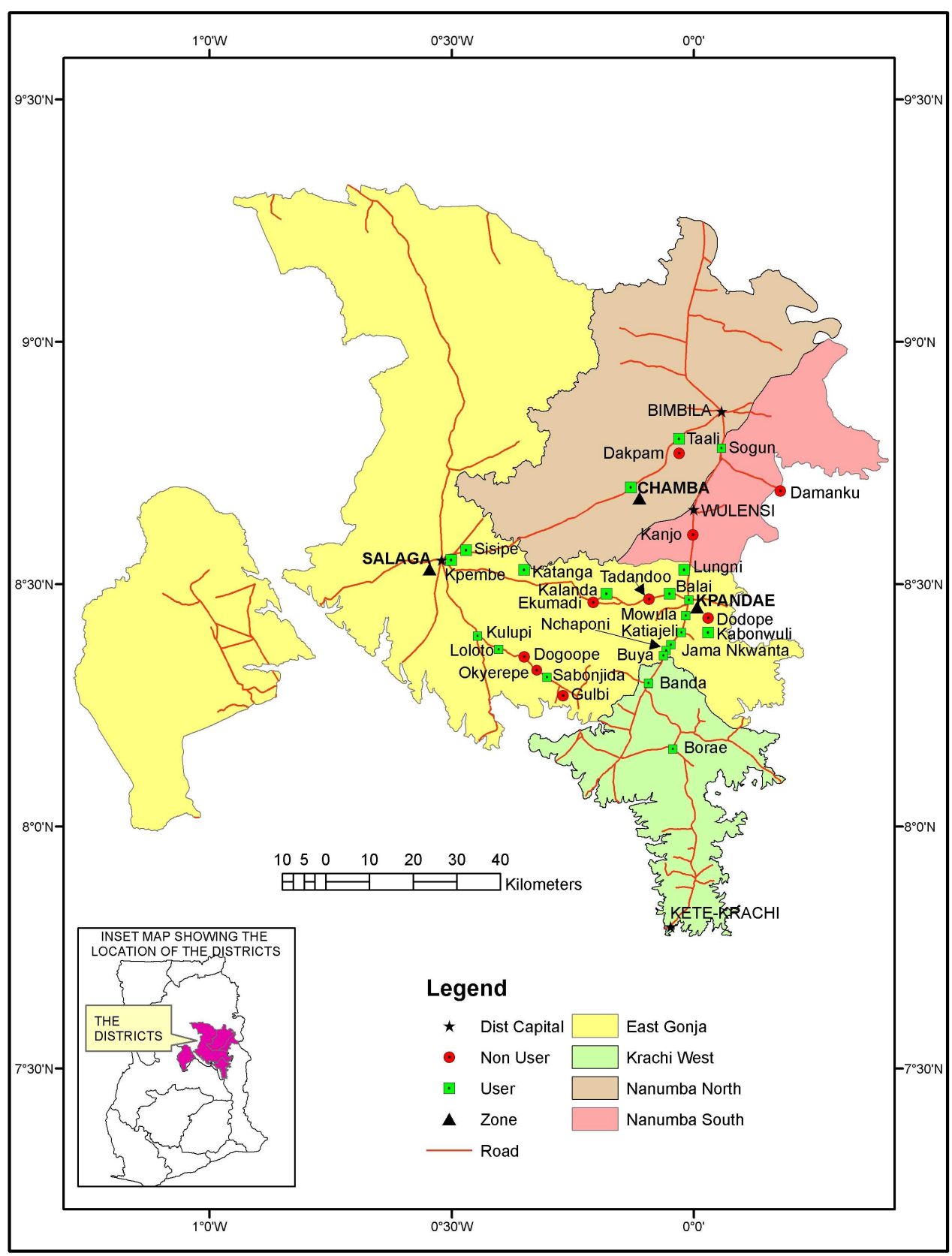

Source: the Geography Department of University of Ghana 
Figure 4: Propensity score distribution in the treated and untreated group

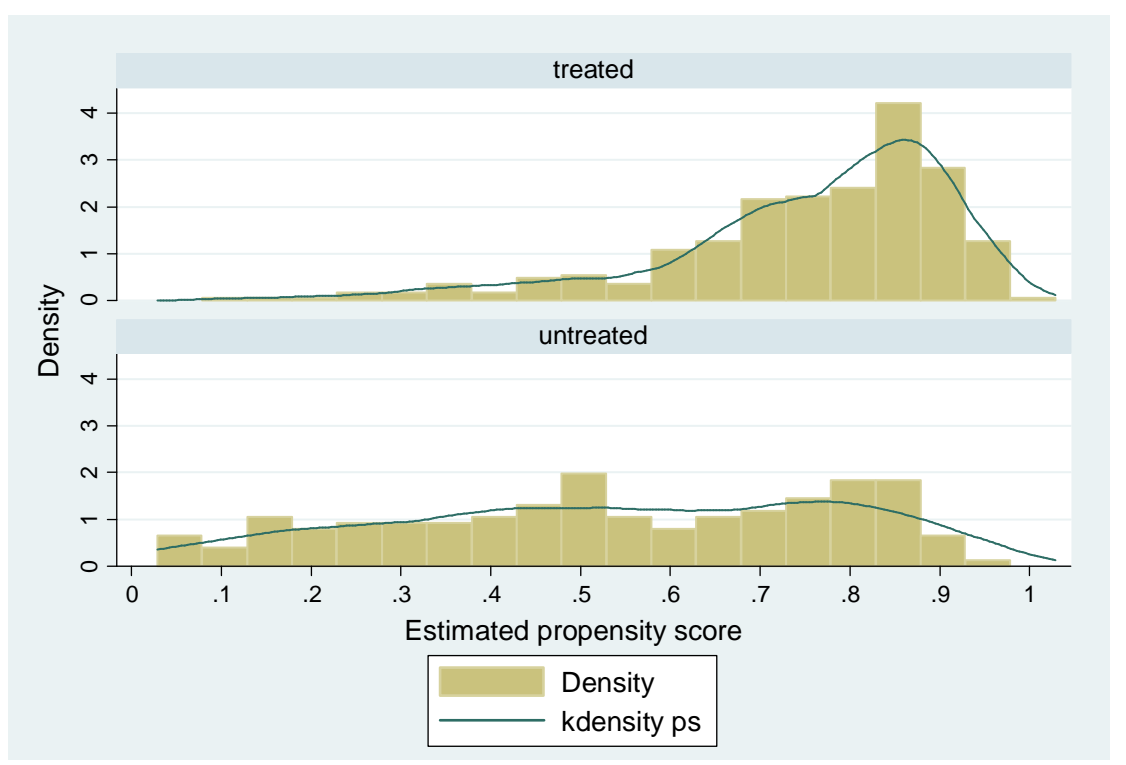

Table 4: Average treatment effect on the treatment

\begin{tabular}{lrlrl} 
estimator & maize & & groundnut & \\
\hline nnm_1_ps & 5.19 & $* * *$ & 6.22 & $\circ$ \\
& 1.74 & & 3.89 & \\
nnm_1_x & 5.88 & $* * *$ & 7.48 & $*$ \\
& 1.91 & & 4.14 & \\
nnm_4_ps & 5.75 & $* * *$ & 10.87 & $* * *$ \\
& 1.37 & & 3.61 & \\
nnm_4_x & 5.75 & $* * *$ & 10.10 & $* * *$ \\
& 1.42 & & 3.40 & \\
ps_kernel & 5.38 & $* * *$ & 10.31 & $* *$ \\
& 1.37 & & 4.21 & \\
ps_llr & 4.44 & & 6.29 & \\
& 4.03 & & 9.85 & \\
ols_ps & 4.17 & $* * *$ & 8.48 & $* * *$ \\
& 1.12 & & 2.75 & \\
ols_x & 3.95 & $* * *$ & 10.88 & $* * *$ \\
& 1.16 & & 2.84 & \\
\hline $\mathrm{n}$ & 219 & & 160 & \\
\hline
\end{tabular}

Note: Standard errors are in italics. Three asterisks *** (resp. ${ }^{* *}$ ) denote rejection of the null hypothesis $(a t t=0)$ at the $1 \%($ resp. 5\%) significance level. $n n m$ is the nearest neighbor matching estimator, kernel is the kernel-based matching estimator, and $l l r$ the local linear matching estimator; $x$ refers to the multivariate matching based on the distance between vectors $X_{i}$ and $X_{j}$ while $p s$ refers to univariate matching based on the distance between propensity scores. The number of matches used for $n n m$ can be 1 or $4 . n$ is the sample size. 
Table 5: Access to credit

\begin{tabular}{lrrrr} 
Credit provider $\# \mathbf{1}$ & Ecamic & Prestat & untreated & Total \\
\hline no credit & $\mathbf{2 8}$ & $\mathbf{2 9}$ & $\mathbf{9 4}$ & 150 \\
friend & 8 & 8 & 18 & 34 \\
family & 5 & 5 & 25 & 35 \\
trader & 0 & 2 & 45 & 47 \\
credit union & $\mathbf{1 2 9}$ & $\mathbf{1 0 9}$ & $\mathbf{7}$ & 245 \\
microfi instit & 19 & 20 & 0 & 39 \\
SEND business prog & 2 & 0 & 0 & 2 \\
bank & 5 & 30 & 11 & 46 \\
\hline Total & 196 & 203 & 200 & 599
\end{tabular}

Table 6: Use of credit

\begin{tabular}{lrrrr} 
Credit $2008 \# 1$ & Ecamic & Prestat & no-SEND & Total \\
\hline no credit & 28 & 29 & 94 & 151 \\
food & 2 & 8 & 6 & 16 \\
livestock & 1 & 3 & 3 & 7 \\
inputs & $\mathbf{1 2 4}$ & $\mathbf{1 2 2}$ & $\mathbf{7 9}$ & $\mathbf{3 2 5}$ \\
equipments & $\mathbf{3 2}$ & $\mathbf{2 7}$ & $\mathbf{1 6}$ & $\mathbf{7 5}$ \\
other & 9 & 14 & 2 & 25 \\
\hline Total & 196 & 203 & 200 & 599
\end{tabular}


Table 7: ATT controlling for credit access

\begin{tabular}{|c|c|c|c|c|}
\hline estimator & maize & \multicolumn{3}{|c|}{ groundnut } \\
\hline \multirow{2}{*}{$\mathrm{nnm} \_1 \_\mathrm{ps}$} & 5.20 & $* * *$ & 8.89 & $*$ \\
\hline & 1.82 & & 5.24 & \\
\hline \multirow[t]{2}{*}{$\mathrm{nnm}_{-}{ }_{-} \mathrm{x}$} & 5.88 & $* * *$ & 7.69 & $* *$ \\
\hline & 1.92 & & 3.92 & \\
\hline \multirow[t]{2}{*}{$\mathrm{nnm} \_4$ _ps } & 5.92 & $* * *$ & 10.42 & $* * *$ \\
\hline & 1.41 & & 3.60 & \\
\hline \multirow[t]{2}{*}{$n n m \_{ }_{2} \mathrm{x}$} & 5.88 & $* * *$ & 9.82 & $* * *$ \\
\hline & 1.42 & & 3.39 & \\
\hline \multirow[t]{2}{*}{ psm_kernel } & 5.03 & $* * *$ & 11.69 & * \\
\hline & 1.26 & & 6.72 & \\
\hline \multirow[t]{2}{*}{ psm_llr } & -0.60 & & 38.87 & $* *$ \\
\hline & 63.64 & & 17.89 & \\
\hline \multirow[t]{2}{*}{ ols_ps } & 4.09 & $* * *$ & 8.89 & $* * *$ \\
\hline & 1.12 & & 2.87 & \\
\hline \multirow[t]{2}{*}{ ols_x } & 3.91 & $* * *$ & 10.62 & $* * *$ \\
\hline & 1.16 & & 2.98 & \\
\hline $\mathrm{n}$ & 217 & & 158 & \\
\hline \multicolumn{5}{|c|}{$\begin{array}{l}\text { Note: Standard errors are in italics. Three asterisks } \\
\left.* * * \text { (resp. } *^{*}\right) \text { denote rejection of the null hypothesis } \\
(\text { att }=0 \text { ) at the } 1 \% \text { (resp. } 5 \% \text { ) significance level. nnm } \\
\text { is the nearest neighbor matching estimator, kernel is the } \\
\text { kernel-based matching estimator, and llr the local linear } \\
\text { matching estimator; } x \text { refers to the multivariate matching } \\
\text { based on the distance between vectors } X_{i} \text { and } X_{j} \text { while } \\
p s \text { refers to univariate matching based on the distance } \\
\text { between propensity scores. The number of matches used } \\
\text { for } n n m \text { can be } 1 \text { or } 4 \text {. } n \text { is the sample size. }\end{array}$} \\
\hline
\end{tabular}


Table 8: ATT controlling for collective marketing effect

\begin{tabular}{|c|c|c|c|c|}
\hline estimator & maize & \multicolumn{3}{|c|}{ groundnut } \\
\hline \multirow[t]{2}{*}{$\mathrm{nnm}_{-} 1_{-} \mathrm{ps}$} & 5.45 & $* * *$ & 6.96 & \\
\hline & 1.96 & & 6.24 & \\
\hline \multirow{2}{*}{$\mathrm{nnm}{ }_{-}{ }_{-} \mathrm{x}$} & 5.76 & $* * *$ & 6.18 & \\
\hline & 2.03 & & 4.68 & \\
\hline \multirow[t]{2}{*}{$\mathrm{nnm} \_4$ _ps } & 6.09 & $* * *$ & 10.14 & $* * *$ \\
\hline & 1.51 & & 3.80 & \\
\hline \multirow[t]{2}{*}{$\mathrm{nnm}{ }_{-}^{4}{ }_{-} \mathrm{x}$} & 5.82 & $* * *$ & 9.82 & $* * *$ \\
\hline & 1.43 & & 3.39 & \\
\hline \multirow[t]{2}{*}{ psm_kernel } & 5.95 & $* * *$ & 18.41 & $* * *$ \\
\hline & 1.51 & & 5.08 & \\
\hline \multirow{2}{*}{ psm_llr } & 2.27 & & 39.48 & $* *$ \\
\hline & 19.16 & & 16.80 & \\
\hline \multirow[t]{2}{*}{ ols_ps } & 4.28 & $* * *$ & 9.59 & $* * *$ \\
\hline & 1.25 & & 3.25 & \\
\hline \multirow[t]{2}{*}{ ols_x } & 3.94 & $* * *$ & 10.00 & $* * *$ \\
\hline & 1.28 & & 3.23 & \\
\hline $\mathrm{n}$ & 201 & & 156 & \\
\hline \multicolumn{5}{|c|}{$\begin{array}{l}\text { Note: Standard errors are in italics. Three asterisks } \\
* * * \text { (resp. }{ }^{* *} \text { ) denote rejection of the null hypothesis } \\
(\text { att }=0 \text { ) at the } 1 \% \text { (resp. } 5 \% \text { ) significance level. nnm } \\
\text { is the nearest neighbor matching estimator, kernel is the } \\
\text { kernel-based matching estimator, and } l l r \text { the local linear } \\
\text { matching estimator; } x \text { refers to the multivariate matching } \\
\text { based on the distance between vectors } X_{i} \text { and } X_{j} \text { while } \\
\text { ps refers to univariate matching based on the distance } \\
\text { between propensity scores. The number of matches used } \\
\text { for } n n m \text { can be } 1 \text { or } 4 . n \text { is the sample size. }\end{array}$} \\
\hline
\end{tabular}

